\title{
Distribution of cerebral microbleeds in the East and West
}

\author{
Individual participant meta-analysis
}

Yusuke Yakushiji, MD, PhD, * Duncan Wilson, MD, PhD, * Gareth Ambler, PhD, Andreas Charidimou, MD, PhD, Alexa Beiser, PhD, Mark A. van Buchem, MD, PhD, Charles DeCarli, MD, Ding Ding, MPH, PhD,

Villi Gudnason, MD, PhD, Hideo Hara, MD, PhD, Toshio Imaizumi, MD, PhD, Katsuhiko Kohara, MD, PhD,

Hyung-Min Kwon, MD, PhD, Lenore J. Launer, PhD, Vincent Mok, MD, Thanh Phan, PhD,

Sarah R. Preis, ScD, José Rafael Romero, MD, Sudha Seshadri, MD, Velandai Srikanth, MD, PhD,

Yuki Takashima, MD, PhD, Yoshito Tsushima, MD, PhD, Zhaolu Wang, PhD, Philip A. Wolf, MD,

Yunyun Xiong, MD, PhD, Shuhei Yamaguchi, MD, PhD, and David J. Werring, FRCP, PhD

Neurology ${ }^{\circledR}$ 2019;92:e1086-e1097. doi:10.1212/WNL.0000000000007039

\section{Abstract \\ Objective}

We investigated differences in the anatomical distribution of cerebral microbleeds (CMBs) on MRI, hypothesized to indicate the type of underlying cerebral small vessel disease (SVD), between Eastern and Western general populations.

\section{Methods}

We analyzed data from 11 studies identified by a PubMed search between 1996 and April 2014 according to the Preferred Reporting Items for a Systematic Review and Meta-analysis of Individual Participant Data. Study quality measures indicated low or medium risk of bias. We included stroke-free participants from populations aged between 55 and 75 years, categorized by geographic location (Eastern or Western). We categorized CMB distribution (strictly lobar, deep and/or infratentorial [D/I], or mixed [i.e., CMBs located in both lobar and D/I regions]). We tested the hypothesis that Eastern and Western populations have different anatomical distributions of CMBs using multivariable mixed effects logistic regression analyses adjusted for age, sex, and hypertension and clustering by institution.

\section{Results}

Among 8,595 stroke-free individuals (mean age [SD] 66.7 [5.6] years; 48\% male; 42\% from a Western population), 624 (7.3\%) had CMBs (strictly lobar in 3.1\%; D/I or mixed in 4.2\%). In multivariable mixed effects models, Eastern populations had higher odds of D/I or mixed CMBs (adjusted odds ratio 2.78, 95\% confidence interval [CI] 1.77-4.35) compared to Western populations. Eastern populations had a higher number of D/I or mixed CMBs (adjusted prevalence ratio $2.83,95 \%$ CI $1.27-6.31$ ).

\section{Conclusions}

Eastern and Western general populations have different anatomical distributions of CMBs, suggesting differences in the spectrum of predominant underlying SVDs, with potential implications for SVD diagnosis and treatment.

\footnotetext{
*These authors contributed equally to this work.
}

From the Stroke Research Center, Department of Brain Repair \& Rehabilitation, Institute of Neurology (Y.Y., D.W., A.C., D.J.W.), and Department of Statistical Science (G.A.), UCL, London, UK; Division of Neurology (Y.Y., H.H.), Department of Internal Medicine, Saga University Faculty of Medicine, Japan; Department of Neurology (A.B., S.R.P., J.R.R., S.S., P.A.W.), Boston University and the NHLBI's Framingham Heart Study; Department of Biostatistics (A.B., S.R.P.), Boston University, MA; Department of Radiology (M.A.v.B.), Leiden University Medical Center, the Netherlands; Department of Neurology (C.D.), University of California Davis; Department of Neurology (D.D.), Huashan Hospital, Fudan University, Shanghai, China; Icelandic Heart Association (V.G.), Kopavogur; University of Iceland (V.G.), Reykjavik; Department of Neurosurgery (T.I.), Kushiro City General Hospital; Faculty of Collaborative Regional Innovation (K.K.), Ehime University, Matsuyama, Japan; Department of Neurology (H.-M.K.), SMG-SNU Boramae Medical Center, Seoul, Republic of Korea; Intramural Research Program (L.J.L.), National Institute on Aging, Bethesda, MD; Therese Pei Fong Chow Research Center for Prevention of Dementia (V.M., Z.W., Y.X.), Department of Medicine and Therapeutics, The Chinese University of Hong Kong, China; Stroke and Aging Research Group, Department of Medicine, School of Clinical Science at Monash Health (T.P., V.S.), and Department of Medicine, Peninsula Health and Clinical School, Central Clinical School (V.S.), Monash University, Melbourne, Australia; Center for Emotional and Behavioral Disorders (Y. Takashima), Hizen Psychiatric Center, Saga, Japan; Department of Diagnostic Radiology and Nuclear Medicine (Y. Tsushima), Gunma University Graduate School of Medicine; Research Program for Diagnostic and Molecular Imaging (Y. Tsushima), Division of Integrated Oncology Research, Gunma University Initiative for Advanced Research, Maebashi; and Department of Neurology (S.Y.), Faculty of Medicine, Shimane University, Izumo, Japan.

Go to Neurology.org/N for full disclosures. Funding information and disclosures deemed relevant by the authors, if any, are provided at the end of the article. 


\section{Glossary}

$\mathbf{C A A}=$ cerebral amyloid angiopathy; $\mathbf{C I}=$ confidence interval; $\mathbf{C M B}=$ cerebral microbleed; $\mathbf{D} / \mathbf{I}=$ deep and/or infratentorial; GE T2*-WI = gradient-echo T2*-weighted imaging; $\mathbf{I C H}=$ intracerebral hemorrhage; IPD = individual participant data; $\mathbf{O R}=$ odds ratio; $\mathbf{P R}=$ prevalence ratio; $\mathbf{S V D}=$ small vessel disease.

Sporadic cerebral small vessel disease (SVD) is one of the commonest age-related pathologic processes in the brain, and plays a crucial role in stroke and dementia. ${ }^{1}$ Hypertensive arteriopathy and cerebral amyloid angiopathy (CAA) are the most common forms of SVD. ${ }^{1,2}$ Effective treatment and prevention for SVD and its associated clinical phenotypes (including spontaneous intracerebral hemorrhage $[\mathrm{ICH}]$ and dementia) requires a better understanding of the mechanisms and underlying spectrum of SVD.

Cerebral microbleeds (CMBs) detected using blood-sensitive MRI sequences are histologically characterized by the presence of hemosiderin around small vessels, ${ }^{3}$ and are a validated marker of SVD. ${ }^{4,5}$ CMBs are unique among SVD imaging biomarkers because of the well-established association between the topographic distribution of CMBs and pathology of SVD: CMBs in the deep and/or infratentorial (D/I) areas (with or without lobar areas) are associated with known markers of hypertensive arteriopathy, whereas CMBs in strictly lobar regions are associated with CAA., ${ }^{2,6-8}$

There are major differences in the epidemiology of $\mathrm{ICH}$, a key clinical phenotype of SVD, by geography or ethnicity; for example, there is a 2-fold higher incidence in Eastern compared to Western countries. ${ }^{9,10}$ Thus, there is major interest in whether the spectrum of SVD pathology differs between different geographic populations and ethnicities. ${ }^{2}$ However, few large-scale in vivo comparisons of SVD pathologies across populations have been reported. In a large stroke-free individual participant data (IPD) meta-analysis, we tested the hypothesis ${ }^{11,12}$ that the anatomical distribution of CMBs differs between Eastern and Western populations.

\section{Methods}

Our study was performed and reported in line with the Preferred Reporting Items for a Systematic Review and Metaanalysis of Individual Participant Data (the PRISMA-IPD Statement) guidelines ${ }^{13}$ and the Meta-analysis of Observational Studies in Epidemiology. ${ }^{14}$

\section{Search of eligible literatures and cohorts}

We established an international collaborative network to increase the scale of data available and maximize scientific and statistical power. ${ }^{15}$ We undertook this study in accordance with a protocol finalized on May 20, 2014, and approved by the Distribution of the Cerebral Microbleeds in Multiple Eastern and Western populations (DICOM) study collaborators. As shown in the flow diagram of study selection (figure 1), to find articles describing CMBs in general populations, 2 authors (Y.Y. and A.C.) searched PubMed between January 1, 1996, and April 30, 2014, using the predetermined search terms "cerebral microbleed(s)" or "micro(-)h(a)emorrhage(s)" in association with "general," "community" or "healthy" or "population" or "asymptomatic." We also searched reference lists from all included articles and the authors' own files. Articles not published in English or Japanese and case reports were excluded. We found 39 potential articles. Final inclusion criteria were as follows: (1) inclusion of information on prevalence of CMBs on MRI sequences sensitive to magnetic susceptibility effects (i.e., blood-sensitive MRI); (2) inclusion of information on hypertension and/or blood pressure values; and (3) if 2 or more eligible articles were published from the same cohort, the article evaluating the larger number of participants was selected. After sending a copy of the protocol and invitation to collaborate to the corresponding authors of the selected 13 articles that were eligible for inclusion, ${ }^{11,16-27}$ followed by 1 or 2 reminders, we included 11 cohorts (table 1 ) with confirmation of provision of patient-level data. ${ }^{11,16-25}$ The authors of one study did not respond to the invitation to participate. ${ }^{26}$ Another cohort (Rotterdam Scan Study) was not included in the primary analysis because the study had a policy of not sharing patient-level data, ${ }^{27}$ but was included in group data analysis for prevalence of $A P O E 4$ carriers (described below). Detailed data of the 28 excluded articles are available from Dryad (supplemental material, including supplemental reverences and table, doi.org/10.5061/dryad.n459dm5).

\section{Grouping by geographical origin}

All individuals in cohorts from Japan, South Korea, and China were defined by geographical origin as the Eastern population, in which all participants were East Asian. Individuals in cohorts from Iceland, Australia, and the United States were defined by geographical origin as the Western population (all participants from the Icelandic and Australian cohorts were Caucasian; participants in the cohort from the United States were predominantly Caucasian). Eastern population samples included 6 "medical check-up" cohorts (in which participants underwent health screening tests of the brain, including brain MRI, at their own expense) and 2 population-based cohorts, while all Western population samples were population-based cohorts.

\section{Ethics}

Protocols were approved by the institutional review board for 7 cohorts, ${ }^{11,16-18,21,23,25}$ while the other 4 cohorts ${ }^{19,20,22,24}$ had approved in advance the provision of patient-level data for secondary use in collaborative research. Because cohorts shared only anonymized data, no individual consent for this pooled analysis was required. 
Table 1 Characteristics of included cohorts

\begin{tabular}{|c|c|c|c|c|c|c|c|c|c|c|c|}
\hline & \multicolumn{8}{|c|}{ Eastern population } & \multicolumn{3}{|c|}{ Western population } \\
\hline & Ohta ${ }^{16}$ & Hakodate ${ }^{17}$ & Toon $^{18}$ & Izumo $^{19}$ & Sefuri ${ }^{20}$ & Kashima ${ }^{11}$ & Seoul $^{21}$ & Shanghai ${ }^{22}$ & Reykjavik $^{23}$ & Tasmania $^{24}$ & Framingham ${ }^{25}$ \\
\hline \multicolumn{12}{|l|}{ No. of participants } \\
\hline At local study & 450 & 209 & 443 & 2,012 & 368 & $1,575^{\mathrm{a}}$ & 1,452 & 278 & 4,368 & 368 & 1,965 \\
\hline Included in this study $(\%)^{b}$ & $173(38)$ & $104(50)$ & $350(79)$ & $1,602(76)$ & $226(61)$ & $965(61)$ & $1,302(90)$ & $234(84)$ & $2,127(49)$ & $247(67)$ & $1,265(64)$ \\
\hline Nationality/population type & JPN/MC & JPN/MC & JPN/MC & $J P N / M C$ & JPN/PB & JPN/MC & KOR/MC & $\mathrm{CHN} / \mathrm{PB}$ & ISL/PB & AUS/PB & USA/PB \\
\hline Age, y, median (SD) & $59.6(4.5)$ & $61.9(5.2)$ & $66.7(5.1)$ & $63.9(5.2)$ & $64.0(5.8)$ & $62.9(5.0)$ & $68.6(2.9)$ & $66.9(4.9)$ & $71.6(2.4)$ & $67.8(4.1)$ & $64.5(5.8)$ \\
\hline Sex, male, \% & 65.3 & 52.9 & 35.7 & 51.9 & 48.2 & 45.3 & 57.6 & 45.7 & 40.6 & 55.1 & 47.2 \\
\hline \multicolumn{12}{|l|}{ HTN criteria } \\
\hline$B P \geq 140 / 90 \mathrm{~mm} \mathrm{Hg}$ & Used & Used & Used & Used & Used & Used & Used & Used & Used & Used & Used \\
\hline Medication & Used & Used & Used & Used & Used & Used & Used & Used & Used & Used & Used \\
\hline Self-report & Used & Not used & Not used & Not used & Not used & Not used & Not used & Not used & Not used & Used & Not used \\
\hline HTN, n (\%) & $56(32)$ & $49(47)$ & $197(56)$ & $711(44)$ & $82(36)$ & $407(42)$ & $640(49)$ & $117(50)$ & $1,590(75)$ & $174(70)$ & $689(55)$ \\
\hline \multicolumn{12}{|l|}{ CMBs criteria } \\
\hline Diameter, $\mathrm{mm}$ & $<10$ & $<10$ & $2-10$ & $2-10$ & $\leq 10$ & $\leq 10$ & $<5$ & $2-10$ & ND & $2-10$ & $\leq 10$ \\
\hline Rating scale & MARS & MARS & MARS & MARS & MARS & MARS & MARS & MARS & MARS $^{\mathrm{C}}$ & MARS & MARS \\
\hline \multicolumn{12}{|l|}{ GE-MRI protocol } \\
\hline Magnetic field strength, $T$ & 1.0 & 1.5 & 3.0 & 1.5 & 1.0 & 1.5 & 1.5 & 1.5 & 1.5 & 1.5 & 1.5 \\
\hline Echo time, ms & 30 & 26 & 7 & 25 & 20 & 20 & 15 & 30 & 50 & 15 & 26 \\
\hline \multicolumn{12}{|l|}{ CMBs distribution, $n(\%)^{d}$} \\
\hline CMB presence (all) ${ }^{\mathrm{e}}$ & $7(4)$ & $11(11)$ & $15(4)$ & $77(5)$ & $9(4)$ & $102(11)$ & $122(9)$ & $18(8)$ & $176(8)$ & $11(4)$ & $76(6)$ \\
\hline Strictly lobar CMBs & $0(0)$ & $3(3)$ & $5(1)$ & $16(1)$ & $1(0.5)$ & $38(4)$ & $30(2)$ & $7(3)$ & $116(5)$ & $2(1)$ & $49(4)$ \\
\hline D/l or mixed CMBs & $7(4)$ & $8(8)$ & $10(3)$ & $61(4)$ & $8(4)$ & $64(7)$ & $92(7)$ & $11(5)$ & $60(3)$ & $9(4)$ & $27(2)$ \\
\hline
\end{tabular}

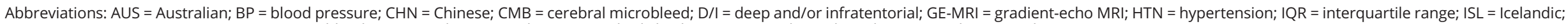
$\mathrm{JPN}=$ Japanese; KOR = Korean; MARS = Microbleed Anatomical Rating Scale; $\mathrm{MC}=$ medical checkup; PB = population-based; ND = not determined.

${ }^{a}$ Additional data $(n=296)$ were provided by the corresponding author of the publication.

${ }^{b}$ Proportion (\%) of participants included in this study among participants at local study.

Similar to MARS.

Proportion (\%) of participants with each CMBs distribution among participants at local study.

e Totals may not be exact due to rounding. 
Figure 1 Preferred Reporting Items for a Systematic Review and Meta-analysis of Individual Participant Data (PRISMA-IPD) flow diagram

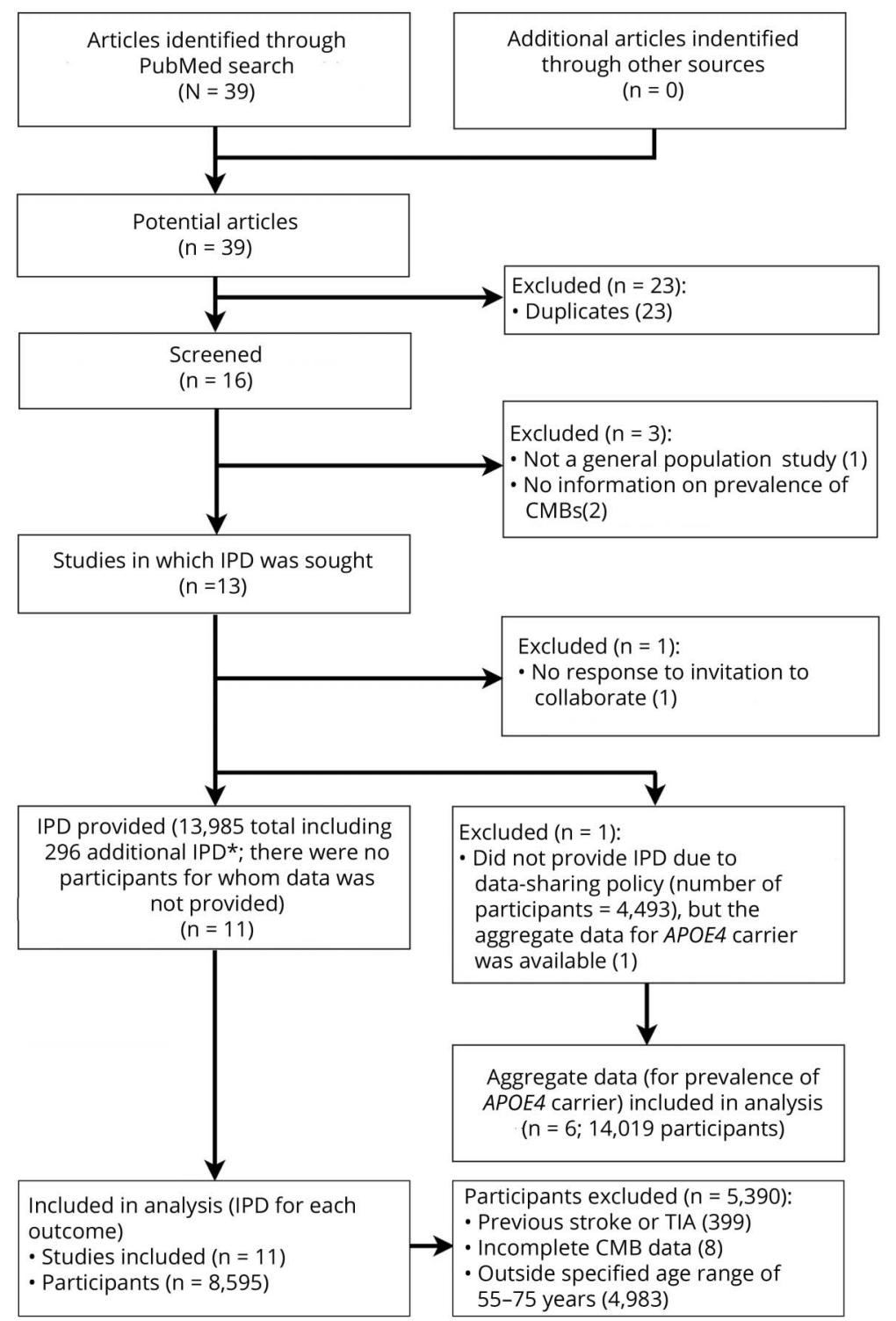

The search of electronic databases (PubMed between January 1, 1996, and April 30, 2014: no articles identified through other sources), using English and Japanese language limit, performed by 2 authors (Y.Y. and A.C.), yielded 39 publications. After 23 duplicates were removed, we identified 16 potential articles. Of those that were reviewed in full-text, we invited 13 independent studies for collaboration with providing individual data. Finally, we included 11 studies that could provide individual data. $\mathrm{CMB}=$ cerebral microbleed; IPD = individual participant data. *Additional data $(n=296)$ were provided by the corresponding author of the publication. ${ }^{11}$

\section{Data collection}

On January 2, 2016, following necessary regulatory approvals, we proceeded to collect IPD of age at MRI, sex, presence of hypertension (as defined by local protocol), CMBs number, and used anatomical rating scale for CMBs. ${ }^{28,29}$ Information on magnetic field strength and echo time for blood-sensitive MRI, both of which could affect CMBs rating, ${ }^{5}$ were obtained from published articles. Some eligible studies for inclusion in our study had data available for APOE4 allele, a known marker for CAA, especially if present concurrently with $\mathrm{CMB}$ s located in strictly lobar regions. ${ }^{7,30}$ We therefore obtained the prevalence of APOE4 carrier from published or unpublished meta-data of included cohorts, ${ }^{24,25,31-33}$ and published meta-data from the Rotterdam Scan Study. ${ }^{34}$

\section{Criteria and MRI protocol}

Criteria for hypertension, $\mathrm{CMB}$ definition, and information on blood-sensitive MRI sequences in each cohort are summarized in table 1 . All cohorts defined hypertension as stage 1 or higher hypertension status according to the seventh report of the Joint National Committee on Prevention, Detection, Evaluation, and Treatment of High Blood Pressure (JNC7) criteria: systolic blood pressure $\geq 140 \mathrm{~mm} \mathrm{Hg}$ and/or diastolic blood pressure $\geq 90 \mathrm{~mm} \mathrm{Hg}^{35}$ In addition, medication (i.e., use of antihypertensive drugs: in 10 cohorts) $)^{11,16-24}$ or self-report of history of hypertension (in 2 cohorts) ${ }^{16,24}$ were also used to define hypertension in several cohorts. In all included cohorts, $\mathrm{CMB}$ was detected on gradient-echo $\mathrm{T} 2{ }^{*}$ weighted imaging (GE T2*-WI) MRI as a rounded area of signal loss according to recent consensus. ${ }^{5,28,29}$ Maximum and 
minimum diameters of $\mathrm{CMBs}$ ranged within 5-10 and 0-2 $\mathrm{mm}$ (the Age, Gene/Environment Susceptibility [AGES]-Reykjavik cohort $^{23}$ did not use size criteria for CMBs). CMBs were evaluated by local laboratory review. If required, collaborators re-rated according to validated rating scales. ${ }^{28,29}$ Magnetic field strength and echo time for GE T2*WI MRI ranged from 1.0 to $3.0 \mathrm{~T}$ and 7 to $50 \mathrm{~ms}$, respectively.

\section{Definition of CMBs category}

CMBs were categorized into different anatomical regions including lobar (cortical and subcortical regions); deep (basal ganglia, thalamus, internal capsule, external capsule, corpus callosum, and deep and periventricular white matter); and infratentorial areas (brainstem and cerebellum). ${ }^{8,28}$ Participants were divided into no CMBs and CMBs present ( 1 or more CMBs) groups. The CMBs present group was divided into a "strictly lobar CMBs group" and a "D/I or mixed CMBs group (i.e., participants had CMBs located in strictly deep and/or infratentorial regions or in both lobar and D/I regions)." Regarding CMB burden, we counted the number of CMBs in each anatomical region (all, lobar, deep, and infratentorial region).

\section{Assessment of risk of bias.}

As our primary target data (i.e., distribution of CMBs) were evaluated in cross-sectional observational study of each cohort, the assessments for exposure (i.e., interventions) and outcome (i.e., assessments for quality of follow-up outcomes) were considered as not applicable in this study. For this study deign, the most important bias would be representativeness of cohort (i.e., how the participants of the cohort represent the average of $\mathrm{CMB}$ prevalence in the community). Thus, each cohort was assessed by population type (medical checkup cohort or population cohort). According to the NewcastleOttawa Scale, ${ }^{36}$ a medical check-up cohort was classified as "somewhat representative" of the CMB prevalence in the community, while a population-based cohort was evaluated as truly representative of the whole population.

\section{Statistical analysis}

To increase comparability between the Eastern and Western cohorts, we first defined an age inclusion criterion of 55-75 years (figure 1), because the Western cohorts tended to have much older participants (figure 2). Statistical analysis was performed using STATA version 15.0 (StataCorp LP, College Station, TX). Mixed effects linear regression was used to compare age, whereas mixed effect logistic regression was used for hypertension and sex. We adjusted for clustering by individual institute using random effects. As MRI measures and population type were cluster-level covariates, we compared them between Eastern centers $(n=8)$ and Western centers $(n=3)$ using the Mann-Whitney $U$ test or $\chi^{2}$ test without center clustering, as appropriate. Selection of potential confounders for the following analyses was based on a priori consideration of factors known to be associated with CMBs detection on MRI, including age, sex, and hypertension on the individual level; radiologic factors (magnetic field strength $[1.0,1.5$, or $3.0 \mathrm{~T}]$ and echo time from GE T2*-WI $\mathrm{MRI}$ ); and population type (medical check-up or populationbased), measured on the cohort level.

Figure 2 Frequency distribution of participants by age between the Eastern population and Western population (all collected data of 13,985 participants)

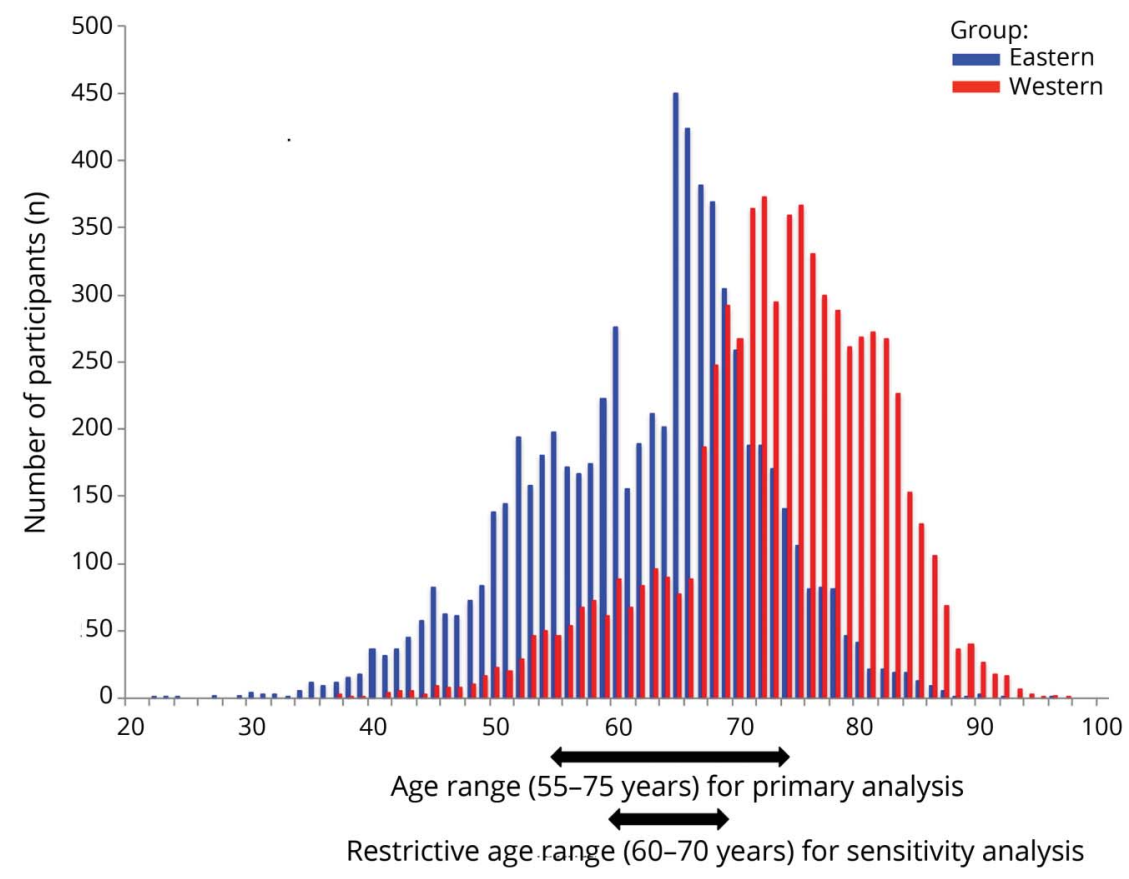

Blue bars indicate participant number of Eastern population (per years of age). Red bars indicate participant number of Western population (per years of age). Arrows indicates age range in primary analysis (upper) and in sensitivity analysis (lower). 
Univariable mixed effects logistic regression was used separately to compare binary (yes/no) imaging characteristics (all CMBs group, strictly lobar $\mathrm{CMB}$ group, and $\mathrm{D} / \mathrm{I}$ or mixed CMBs group) between the Eastern and Western population (each result was presented as an odds ratio $[\mathrm{OR}])$. To compare number of CMBs, we used a mixedeffects negative binomial regression model, again adjusting for institute level clustering. This model was used in preference to a Poisson model as CMB number was heavily skewed to the right. The results are presented as prevalence ratios (PR), which quantify the relative number of CMBs for the Eastern population compared to the Western population. For example, a PR of 1.17 for "CMBs (all)" suggests that there are $17 \%$ more CMBs in the Eastern population compared to the Western population.

Multivariable mixed effects logistic regression was undertaken in a similar manner with the addition of age, sex, and hypertension as fixed effects. MRI measures and population types were not included in the regression analyses as they are cluster level variables. To further decrease the bias of age range difference between the Eastern population and the Western population, we performed sensitivity analyses using an even more restrictive age range (60-70 years). As a further sensitivity analysis, due to the lower interrater reliability for a single $\mathrm{CMB},{ }^{28,29}$ we compared prevalence (but not number) of multiple CMBs (i.e., multiple CMBs [all], multiple strictly lobar CMBs, and multiple D/I or mixed CMBs) in Eastern and Western populations, using the same age range of 55-75 years as for the primary analyses.
We used meta-analysis to estimate the prevalence of APOE4 carriers and displayed the results using a forest plot. Heterogeneity was quantified using the $I^{2}$ statistic. Values of $p<0.05$ were considered statistically significant.

\section{Data availability}

Studies participating in this IPD meta-analysis have separate and specific data request and approval policies, depending on local, national, and international laws and regulations. Because of restrictions based on such privacy laws and regulations and informed consent of the participants, data cannot be made freely available in a public repository for the participating studies. Requests for information on procedures and formal data requests can be submitted to investigators from the respective studies. ${ }^{11,16-25}$

\section{Results}

We completed IPD collection from 13,985 participants of 11 cohort studies. Regarding assessments for risk of bias, 6 cohorts were medical check-up cohorts (i.e., somewhat representative of the average of CMBs prevalence in the community) and 5 cohorts were population-based cohorts (i.e., truly representative of the average of $\mathrm{CMB}$ prevalence in the community), indicating low or medium risk of bias. Among those participants, 407 were excluded because of previous symptomatic stroke or TIA $(\mathrm{n}=399)$, or because of incomplete data of CMBs prevalence and number $(n=8)$. Thus, we collected complete data from 13,578 stroke-free individuals (mean age [SD] 67.8 [10.6] years; age range 22-97 years; male 48\%, Western population $49 \%)$. Of these, 1,108 participants (8.2\%)

Table 2 Univariable differences in Eastern population vs Western population with regard to demographics, risk factors, and blood-sensitive MRI measures $(n=8,595)$

\begin{tabular}{|c|c|c|c|c|}
\hline & $\begin{array}{l}\text { Western population } \\
(n=3,639)\end{array}$ & $\begin{array}{l}\text { Eastern population } \\
(n=4,956)\end{array}$ & $\begin{array}{l}\text { Difference for Eastern } \\
\text { population }(95 \% \mathrm{CI})^{\mathrm{a}}\end{array}$ & $p$ Value $^{a}$ \\
\hline Age, y, mean (SD) & $68.9(5.2)^{\mathrm{b}}$ & $65.1(5.3)^{\mathrm{b}}$ & Coef. -3.65 years $(-7.38$ to 0.07$)$ & $0.055^{c}$ \\
\hline Sex, male, n (\%) & $1,597(44)^{b}$ & $2,528(51)^{b}$ & OR 1.13 (0.75-1.69) & 0.564 \\
\hline \multirow[t]{2}{*}{ Hypertension, n (\%) } & $2,453(67)^{\mathrm{b}}$ & $2,259(46)^{b}$ & OR $0.40(0.26-0.61)$ & $<0.001^{d}$ \\
\hline & $\begin{array}{l}\text { Western centers } \\
(n=3)\end{array}$ & $\begin{array}{l}\text { Eastern centers } \\
(n=8)\end{array}$ & Cluster level covariates & $p$ Value ${ }^{\mathrm{e}}$ \\
\hline $\begin{array}{l}\text { MRI field strength, } \\
\text { T, median (IQR) }\end{array}$ & $1.5(1.5-1.5)$ & $1.5(1.3-1.5)$ & NA & 0.697 \\
\hline $\begin{array}{l}\text { MRI echo time, ms, } \\
\text { median (IQR) }\end{array}$ & $26(21-38)$ & $23(18-28)$ & NA & 0.537 \\
\hline $\begin{array}{l}\text { Population type, } \\
\text { population-based, } \\
\text { n (\%) }\end{array}$ & $3(100)$ & $2(25.0)$ & NA & 0.026 \\
\hline
\end{tabular}

Abbreviations: $\mathrm{Cl}$ = confidence interval; Coef = coefficient; IQR = interquartile range; NA = not applicable; OR = odds ratio.

avaluated with adjusting for center clustering.

${ }^{b}$ Values are not adjusted for clustering.

c The Eastern population likely to be younger (but not significant) by average of 3.65 years after adjusting for center clustering.

${ }^{\mathrm{d}}$ Meaning the odds of hypertension are 2.5 times larger in Western population compared to Eastern population.

e As MRI measures and population type were cluster-level covariates, we compared them between Eastern centers $(n=8)$ and Western centers $(n=3)$ using Mann-Whitney $U$ test or $\chi^{2}$ test without center clustering, as appropriate. 
had one or more CMBs: these were strictly lobar in $3.8 \%$ and $\mathrm{D} / \mathrm{I}$ or mixed in $4.4 \%$. After excluding participants $(\mathrm{n}=4,983)$ outside of our specified age range (55-75 years), we included 8,595 (mean age [SD], 66.7 [5.6] years; male 48\%), including 4,956 Eastern individuals (58\%; i.e., the Eastern population) and 3,639 Western individuals (42\%; i.e., the Western population), in the primary analysis. Characteristics of the included cohorts are summarized in table 1.

Univariate differences between the Eastern and Western population with regard to age, sex, and hypertension, after adjusting for center clustering, are shown in table 2. The Eastern population was younger than the Western population (65.1 vs 68.9 years), but this did not reach significance level after adjusting for center clustering (coefficient -3.65 years, 95\% confidence interval $[\mathrm{CI}]-7.38$ to 0.07 , cluster level adjusted $p=0.055)$. There were proportionately more men in the Eastern $(51 \%)$ compared to the Western population (44\%), but no differences were seen (cluster level adjusted $p=0.564$ ). Hypertension was more common in the Western population than the Eastern population ( $46 \%$ in the Eastern vs $67 \%$ in the Western, cluster level adjusted $p<0.001)$. There were no differences in bloodsensitive MRI measures between the Eastern centers $(n=8)$ and the Western centers $(n=3)$. Regarding source population type, population-based study was higher in the Western centers $(p=0.026)$ compared to the Eastern centers.

Among the 8,595 participants, 624 participants (7.3\%) had CMBs. Of these, 267 (3.1\%) participants had strictly lobar CMBs and 357 (4.2\%) had D/I or mixed CMBs (table 3 ).

Table 4 shows the primary results of analyses for the multivariable $\mathrm{OR}$ and $\mathrm{PR}$ (i.e., a rate of $\mathrm{CMBs}$ presence) for the Eastern population (vs the Western population) for each outcome. There were no differences in the prevalence of all CMBs between the populations. However, in multivariable analysis, the Eastern population had a higher prevalence of D/ I or mixed CMBs (multivariable model, OR 2.78, 95\% CI 1.77-4.35, $p<0.001$ ) compared to the Western population. Similar findings were also seen in the multivariable model of sensitivity analyses using more a restrictive age range (multivariable model, OR for Eastern group [vs Western group]: all CMBs, OR 1.69, 95\% CI 0.96-3.00, $p=0.070$; strictly lobar CMBs, OR 0.67, 95\% CI 0.28-1.61, $p=0.369$; D/I or mixed CMBs, OR 3.40, 95\% CI 1.96-5.89, $p<0.001)$. A sensitivity analysis comparing the prevalence of multiple CMBs (i.e., $\geq 2$ CMBs) - using the same age range as the primary analyses - showed similar findings (multivariable model, OR for Eastern group [vs Western group]: all multiple CMBs, OR 1.75, 95\% CI 0.89-3.45, $p=0.105$; multiple D/I or mixed CMBs, OR 3.25, 95\% CI 1.61-6.68, $p=0.001$ ), but a slightly higher prevalence of multiple strictly lobar CMBs in the Western population (multivariable model, OR for Eastern 0.43, 95\% CI 0.17-1.04, $p=0.062$ ). Regarding CMB number, the Eastern population had a higher number of $\mathrm{D} / \mathrm{I}$ or mixed CMBs (multivariable model: 2.83, 95\% CI 1.27-6.31, $p=0.011$ ) in the primary analysis (table 4) and sensitivity
Table 3 Prevalence of cerebral microbleeds (CMBs) in all included participants ( $n=8,595)$ according to Eastern or Western population

\begin{tabular}{|c|c|c|c|}
\hline & $\begin{array}{l}\text { All } \\
(n=8,595)\end{array}$ & $\begin{array}{l}\text { Western } \\
\text { population } \\
(n=4,956)\end{array}$ & $\begin{array}{l}\text { Eastern } \\
\text { population } \\
(n=3,639)\end{array}$ \\
\hline \multicolumn{4}{|c|}{ CMBs prevalence, $\mathrm{n}(\%)^{\mathrm{a}}$} \\
\hline \multicolumn{4}{|l|}{ CMBs (all) } \\
\hline 1 & $422(4.9)$ & $181(5.0)$ & $241(4.9)$ \\
\hline$\geq 2$ & $202(2.4)$ & $82(2.3)$ & $120(2.4)$ \\
\hline Any $(\geq 1)$ & $624(7.3)$ & $263(7.2)$ & 361 (7.3) \\
\hline \multicolumn{4}{|c|}{ Strictly lobar CMBs } \\
\hline 1 & $203(2.4)$ & 120 (3.3) & $83(1.7)$ \\
\hline$\geq 2$ & $64(0.7)$ & $47(1.3)$ & $17(0.3)$ \\
\hline Any $(\geq 1)$ & $267(3.1)$ & $167(4.6)$ & $100(2.0)$ \\
\hline \multicolumn{4}{|c|}{ D/I or mixed CMBs } \\
\hline 1 & $219(2.6)$ & $61(1.7)$ & $158(3.2)$ \\
\hline$\geq 2$ & $138(1.6)$ & $35(1.0)$ & $103(2.1)$ \\
\hline Any $(\geq 1)$ & 357 (4.2) & $96(2.6)$ & $161(5.3)$ \\
\hline
\end{tabular}

CMB number, median

(IQR) for

participants with any

CMBs

\begin{tabular}{cccc}
\hline CMBs group $(\mathbf{n}=\mathbf{6 2 4})$ & $1(1-2)$ & $1(1-2)$ & $1(1-2)$ \\
\hline $\begin{array}{c}\text { Strictly lobar CMBs } \\
\text { group }(\mathbf{n}=\mathbf{2 6 7})\end{array}$ & $1(1-1)$ & $1(1-2)$ & $1(1-1)$ \\
\hline $\begin{array}{c}\text { D/l or mixed CMBs } \\
\text { group }(\mathbf{n}=\mathbf{3 5 7})\end{array}$ & $1(1-2)$ & $1(1-2)$ & $1(1-2)$ \\
\hline
\end{tabular}

Abbreviations: $\mathrm{D} / \mathrm{I}=$ deep and/or infratentorial; IQR = interquartile range. Values indicate raw data (not adjusted for center clustering).

a Totals may not be exact due to rounding.

analysis using a more restrictive age range (multivariable model, PR 3.00, 95\% CI 1.21-7.47, $p=0.018$ ). There was no difference in the number of all CMBs, as well as strictly lobar CMBs, between the Eastern and Western population in the primary analyses (multivariable model, PR for Eastern group [vs Western group]: all CMBs, PR 1.66, 95\% CI 0.80-3.43, p $=0.171$; strictly lobar CMBs, PR 0.61, 95\% CI 0.26-1.43, $p=$ 0.254 ), and the sensitivity analyses using a more restrictive age range (multivariable model, PR for Eastern group [vs Western group]: all CMBs, PR 1.65, 95\% CI 0.71-3.85, $p=0.249$; strictly lobar CMBs, PR 0.51, 95\% CI 0.19-1.36, $p=0.179$ ).

Metadata on the prevalence of APOE4 carriers was available from 6 studies (figure 3: no restriction on age range). The overall pooled estimate (\%) was 24.14 (95\% CI 20.13-28.14); the $I^{2}$ value of $96.3 \%$ suggests considerable heterogeneity between the studies. The prevalence of APOE4 was higher in the Western cohorts of Reykjavik (28.10\%, 95\% CI 26.85-29.35) and Rotterdam (27.10\%, 95\% CI 25.67-28.53), 
Table 4 Primary results of univariable and multivariable odds ratio (OR) and prevalence ratios for Eastern population (vs Western population) for each outcome

\begin{tabular}{|c|c|c|c|c|}
\hline \multirow[b]{2}{*}{ CMBs prevalence $^{a}$} & \multicolumn{2}{|c|}{ Univariable analyses $^{c}$} & \multicolumn{2}{|c|}{ Multivariable analyses $^{d}$} \\
\hline & OR $(95 \% \mathrm{CI})$ & $p$ Value & OR $(95 \% \mathrm{CI})$ & $p$ Value \\
\hline CMBs (all) & $1.05(0.64-1.72)$ & 0.853 & $1.52(0.90-2.59)$ & 0.119 \\
\hline Strictly lobar CMBs & $0.51(0.21-1.24)$ & 0.139 & $0.70(0.29-1.72)$ & 0.439 \\
\hline \multirow[t]{2}{*}{$\mathrm{D} / \mathrm{l}$ or mixed CMBs } & $1.92(1.25-2.94)$ & 0.003 & $2.78(1.77-4.35)$ & $<0.001$ \\
\hline & \multicolumn{2}{|c|}{ Univariable analyses $^{c}$} & \multicolumn{2}{|c|}{ Multivariable analyses $^{d}$} \\
\hline CMB number ${ }^{b}$ & PR $(95 \% \mathrm{Cl})$ & $p$ Value & PR $(95 \% \mathrm{Cl})$ & $p$ Value \\
\hline CMBs (all) & $1.17(0.61-2.21)$ & 0.546 & $1.66(0.80-3.43)$ & 0.171 \\
\hline Strictly lobar CMBs & $0.47(0.20-1.07)$ & 0.930 & $0.61(0.26-1.43)$ & 0.254 \\
\hline D/I or mixed CMBs & $1.70(0.89-3.24)$ & 0.105 & $2.83(1.27-6.31)$ & 0.011 \\
\hline
\end{tabular}

Abbreviations: $\mathrm{Cl}$ = confidence interval; $\mathrm{CMB}=$ cerebral microbleed; $\mathrm{D} / \mathrm{I}$ = deep and/or infratentorial; $\mathrm{PR}=$ prevalence ratio (indicating the relative number of CMBs: for example, the multivariable analysis suggests that there are 2.83 times more D/I or mixed CMBs in the Eastern population compared to the Western population).

a In this analysis ( $n=8,595)$, each category is compared to the reference category of participants having no CMBs.

${ }^{b}$ In each analysis $(n=8,595)$, the reference category is participants with no CMBs, no strictly lobar CMBs, or no D/I or mixed CMBs, as appropriate.

'Variables were analyzed with adjustment for clustering by institution.

${ }^{\mathrm{d}}$ Variables were analyzed with adjustment for age, sex, hypertension, and clustering by institution.

and lower in the Eastern Shanghai cohort $(17.80 \%, 95 \%$ CI 16.40-19.20).

\section{Discussion}

Our large pooled IPD analyses of MRI scans from stroke-free participants provide new large-scale in vivo evidence on the anatomical distribution of CMBs between Eastern and
Western populations, suggesting different underlying patterns of SVD. Our primary results show that the prevalence and the number of D/I or mixed CMBs is higher in Eastern compared to Western populations.

Only a few previous small cohort studies have investigated differences in $\mathrm{CMB}$ prevalence or anatomical pattern between different ethnicities. ${ }^{37-39}$ In a small cohort study, ${ }^{37}$ the

Figure 3 Forest plots of prevalence of APOE4 carriers made with metadata obtained from published or unpublished metadata

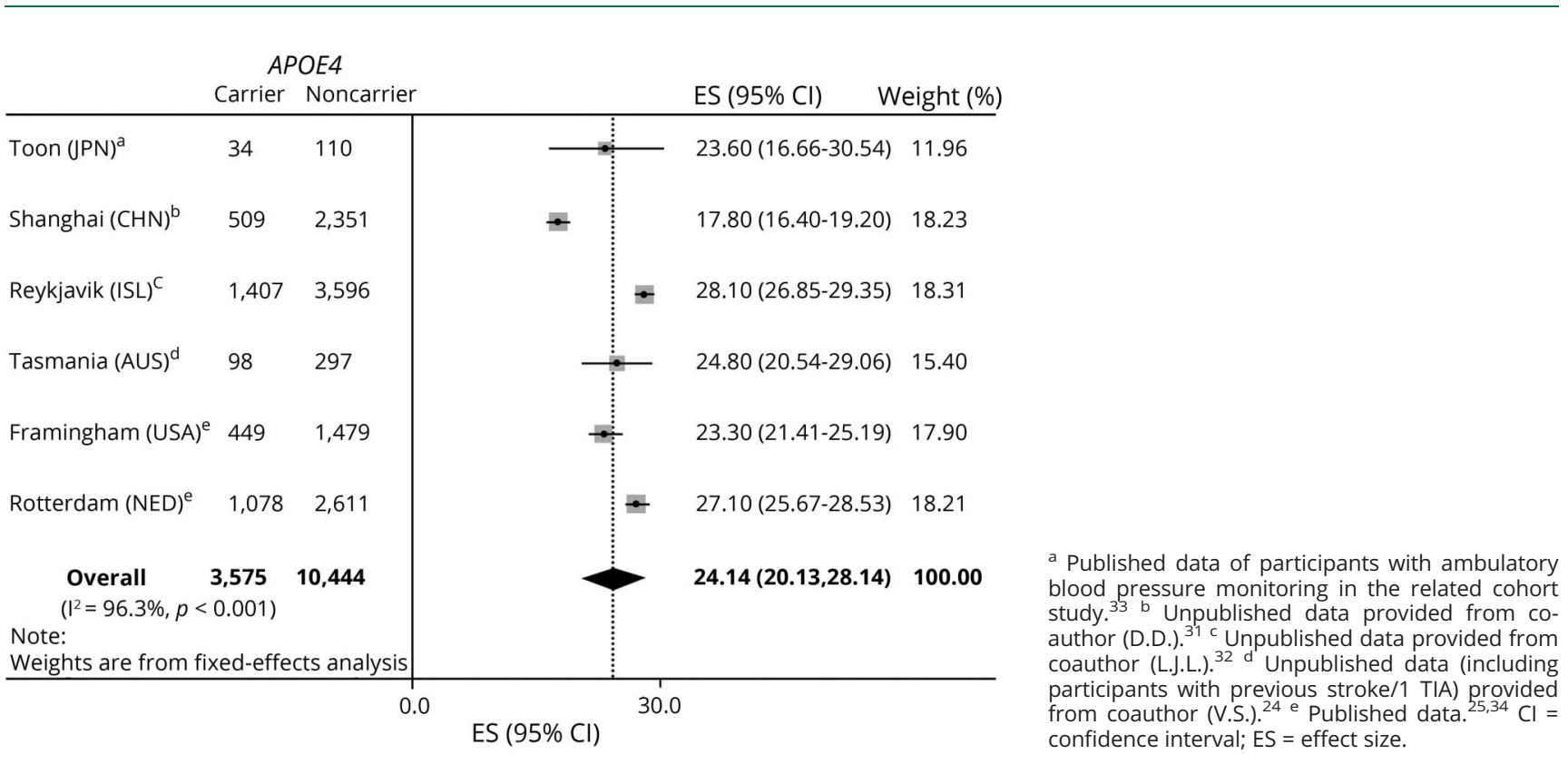


prevalence of CMBs was higher in black patients than in white patients, which was interpreted as being most likely due to the increased rate of hypertension in the black population. Conversely, other individual population-based studies found no association between overall CMBs prevalence and ethnicity, ${ }^{38,39}$ consistent with our result. Only one small single-center multiethnic cohort study investigated associations between $\mathrm{CMB}$ distribution and ethnicity, but found no relationship..$^{39}$ However, our global sample of over 8,000 participants provides much greater statistical power and more reliable estimates of $\mathrm{CMB}$ anatomical patterns across populations.

We found a higher prevalence of $\mathrm{D} / \mathrm{I}$ or mixed CMBs (i.e., a maker of hypertensive arteriopathy) in the Eastern population, despite a lower prevalence of hypertension (including participants taking antihypertensive drugs). One explanation could be that Western populations are more likely to be diagnosed with hypertension and treated early, so that achieving better blood pressure control during midlife might result in a lower prevalence of severe hypertensive arteriopathy compared to Eastern populations. However, hypertension awareness, treatment, and control rates in the 1990s in a Japanese population were similar to those in Western countries. ${ }^{40}$ Since most participants of the Eastern population were Japanese (75\%), this hypothesis might therefore not fully explain our results. Another possible contributory factor might be differences in genetic factors: different ethnicities may have different susceptibilities of small vessels to hypertension (e.g., in the sensitivity of endothelial cells). Furthermore, hypertensive arteriopathy may be driven by factors other than hypertension: for example, some recent evidence suggests that inflammation and endothelial activation may play a larger role than previously considered, and inflammation-mediated endothelial damage appears to differ among ethnicities. ${ }^{41-43}$ One human study demonstrated that despite preserved kidney function and controlled blood pressure, circulating inflammatory endothelial cells, as a marker of endothelial damage, were elevated in black hypertensive patients compared to white hypertensive patients, implying differences in the tolerance of endothelial cells for hypertension across ethnicities. ${ }^{42}$ Among eligible plasma biomarkers, soluble E-selectin, reported as a promising inflammatory biomarker of $\mathrm{CMBs}$, ${ }^{44}$ was also elevated in black hypertensive patients compared to white hypertensive patients. ${ }^{42}$

Although a previous systematic review of autopsy series showed a possible higher prevalence of CAA in the Western population compared to the Eastern population, ${ }^{45}$ our primary analyses did not show a difference in the prevalence and number of strictly lobar CMBs (a putative marker of CAA) between Eastern and Western populations. Indeed, we found a higher prevalence of APOE4 carriers in Western populations, and a sensitivity analysis showed a slightly higher prevalence of multiple strictly lobar CMBs in Western populations $(p=0.062)$; these findings are consistent with a possible higher prevalence of CAA in Western compared to Eastern populations. ${ }^{45}$ However, the diagnostic accuracy of the Boston criteria might be lower in general populations than in hospital cohorts. ${ }^{46}$ Furthermore, the possible lower prevalence of CAA-related ICH in Eastern countries probably reflects a higher incidence of hypertensive brain hemorrhage rather than a decreased incidence of CAA. ${ }^{45}$ Thus, to confirm population differences in CAA, further investigations including neuropathologic data (ideally from population-based autopsy studies) are needed.

The major strengths of our study were as follows: first, our international collaborative analysis pooled IPD from over 8,000 participants, giving us greater power than any single study to investigate differences in number and location of CMBs; second, CMBs were rated on similar MRI sequences using a validated rating scale, ${ }^{28}$ improving reliability (although one Western study [Reykjavík ${ }^{23}$ used a similar but not identical scale); third, each population comprised purely East Asian individuals or purely Caucasian individuals, suggesting that our primary results are due to not only geographical variation, but from true between-population ethnic differences, which include genetic, dietary, culture, medical care, and unknown or unmeasured confounders; finally, we were also able to describe and account for individual subject data on age, sex, hypertension, magnetic field strength, and echo time, which are well-established confounders for CMBs prevalence. ${ }^{4,5,47}$

Some limitations of our study must also be considered. First, there was a difference in prevalence of hypertension among the included cohorts. However, our results adjusted for hypertension as well as for clustering by institution using mixed effect models, to decrease the effect of such bias. Second, the proportion of medical check-up populations selected for selffunded health screening, evaluated as somewhat representative of the true CMBs prevalence in the community, was more common in Eastern cohorts; since health screening tests of the brain were performed partially at the expense of the patient, this might introduce a bias toward more affluent individuals with strong motivation to maintain their own health, and different socioeconomic, educational, diet, and cardiovascular disease profiles. ${ }^{48}$ We minimized this potential confounding influence by adjustment for clustering by institution; however, this will not reduce confounding on an individual level. Third, we did not have information on all potential confounding factors potentially associated with CMBs (e.g., diabetes mellitus, antithrombotic pharmacotherapy, or white matter changes $\left.{ }^{4,7,49}\right)$. Fourth, compared to patient cohort, the frequency of CMBs in this general population cohort was low, and if present, most were single. However, our data reflect the distribution of $\mathrm{CMBs}$ in the population. Fifth, $\mathrm{CMBs}$ were evaluated by local laboratory review, but not by central core laboratory review; however, our protocol specified the use of validated anatomical rating scales, and previous publications from the included studies indicate good reliability for $\mathrm{CMB}$ rating. Sixth, it should be noted that the characteristics of the Eastern population in this study reflected only East Asian populations. Finally, although our study supports a possible 
higher prevalence of hypertensive arteriopathy in Eastern compared to the Western populations, we could not definitively prove this pathologically.

Our large global collaborative individual participant data study adds novel evidence of different patterns of CMBs between Eastern (East Asian) and Western populations, apparently independent of differences in the prevalence of hypertension. Our results suggest that an important determinant of underlying SVD type might be attributable to population ethnic (genetic) susceptibility factors yet to be elucidated, and that optimal SVD treatment and prevention strategies might differ between Eastern and Western populations.

\section{Acknowledgment}

The authors thank the investigators and participants of the cohort studies included in this DICOM study. The work of the study in Toon City ${ }^{18}$ was supported by Grants-in-Aid for Scientific Research from The Ministry of Education, Culture, Sports, Science and Technology of Japan; The Ministry of Health, Labor and Welfare of Japan; the Japan Arteriosclerosis Prevention Fund; a grant-in-aid from Mitsubishi Pharma Research Foundation; and a Research Promotion Award from Ehime University. The work of the study in Izumo City ${ }^{19}$ was partially supported by Mitsubishi Pharma Research Foundation and a Grant-in-Aid for Scientific Research from JSPS. The work of the Kashima Scan Study ${ }^{11}$ was partially supported by a Grant-in-Aid for University Reform 2006 from the Ministry of Education, Culture, Sports, Science and Technology of Japan. The work of the study in Seoul ${ }^{21}$ was supported by a grant from the Boramae Medical Center (032011-9). The work of the Shanghai Aging Study ${ }^{22}$ was supported by a research grant of Shanghai Science and Technology Committee (09DZ1950400, 2009-2012) and Bureau of Health of Shanghai (2009007). The AGESReykjavik Study ${ }^{23}$ was funded by NIH (contract N01-AG12100), the Intramural Research Program of the National Institute on Aging (NIA), the Icelandic Heart Association, and the Icelandic Parliament. The work of the TASCOG ${ }^{24}$ was funded by National Health and Medical Research Council Grants 403000 and 491109. The work of the Framingham Heart Study ${ }^{25}$ was supported by the Framingham Heart Study's National Heart, Lung, and Blood Institute contract (N01-HC-25195) and by grants from the National Institute of Neurological Disorders and Stroke (R01 NS17950), the NIA (R01AG16495, AG08122, AG033193, AG031287, and K23AG038444), and the NIH (1RO1 HL64753, R01 HL076784, and 1 R01 AG028321).

\section{Study funding}

Supported by a Grant-in-Aid for Scientific Research (C), JSPS KAKENHI (Grant 15k10364), and by a research grant from the Japan Brain Dock Society (2015-04).

\section{Disclosure}

Y. Yakushiji received funding from a Grant-in-Aid for Scientific Research (C) and JSPS KAKENHI (Grant 15k10364).
D. Wilson, G. Ambler, A. Charidimou, A. Beiser, M. van Buchem, C. DeCarli, D. Ding, V. Gudnason, H. Hara, T. Imaizumi, K. Kohara, H. Kwon, L. Launer, V. Mok, T. Phan, S. Preis, J. Romero, S. Seshadri, V. Srikanth, Y. Takashima, Y. Tsushima, Z. Wang, P. Wolf, Y. Xiong, S. Yamaguchi, and D. Werring report no disclosures relevant to the manuscript. Go to Neurology.org/ $\mathrm{N}$ for full disclosures.

\section{Publication history}

Received by Neurology May 27, 2018. Accepted in final form October 31, 2018.

Appendix Authors

\begin{tabular}{|c|c|c|c|}
\hline Name & Location & Role & Contribution \\
\hline $\begin{array}{l}\text { Yusuke } \\
\text { Yakushiji, } \\
\text { MD, PhD }\end{array}$ & $\begin{array}{l}\text { UCL, London, UK; } \\
\text { and Saga } \\
\text { University, Japan }\end{array}$ & $\begin{array}{l}\text { Author, chief } \\
\text { investigator }\end{array}$ & $\begin{array}{l}\text { Study concept } \\
\text { and design, } \\
\text { literature search, } \\
\text { data collection, } \\
\text { statistical analysis, } \\
\text { interpretation of } \\
\text { data, drafting/ } \\
\text { revising of } \\
\text { the manuscript, } \\
\text { obtaining funding, } \\
\text { had full access to } \\
\text { all the data in the } \\
\text { study and takes } \\
\text { responsibility for } \\
\text { the integrity of the } \\
\text { data and the } \\
\text { accuracy of the } \\
\text { data analysis }\end{array}$ \\
\hline $\begin{array}{l}\text { Duncan } \\
\text { Wilson, MD, } \\
\text { PhD }\end{array}$ & UCL, London, UK & $\begin{array}{l}\text { Author, chief } \\
\text { investigator }\end{array}$ & $\begin{array}{l}\text { Study concept } \\
\text { and design, major } \\
\text { role in statistical } \\
\text { analysis, data } \\
\text { interpretation, } \\
\text { drafting/revising } \\
\text { of the } \\
\text { manuscript, had } \\
\text { full access to all } \\
\text { the data in the } \\
\text { study and takes } \\
\text { responsibility for } \\
\text { the integrity of } \\
\text { the data and the } \\
\text { accuracy of the } \\
\text { data analysis }\end{array}$ \\
\hline $\begin{array}{l}\text { Gareth } \\
\text { Ambler, PhD }\end{array}$ & UCL, London, UK & Author & $\begin{array}{l}\text { Major role in } \\
\text { statistical } \\
\text { analysis, data } \\
\text { interpretation, } \\
\text { drafting/revising } \\
\text { of the } \\
\text { manuscript }\end{array}$ \\
\hline $\begin{array}{l}\text { Andreas } \\
\text { Charidimou, } \\
\text { MD, PhD }\end{array}$ & UCL, London, UK & Author & $\begin{array}{l}\text { Study concept } \\
\text { and design, } \\
\text { literature search, } \\
\text { data } \\
\text { interpretation, } \\
\text { revising of the } \\
\text { manuscript }\end{array}$ \\
\hline $\begin{array}{l}\text { Alexa Beiser, } \\
\text { PhD }\end{array}$ & $\begin{array}{l}\text { Boston } \\
\text { University and } \\
\text { the NHLBI's } \\
\text { Framingham } \\
\text { Heart Study, MA }\end{array}$ & Author & $\begin{array}{l}\text { Data collection, } \\
\text { data } \\
\text { interpretation, } \\
\text { revising of the } \\
\text { manuscript }\end{array}$ \\
\hline
\end{tabular}

Continued 
Appendix (continued)

\begin{tabular}{|c|c|c|c|}
\hline Name & Location & Role & Contribution \\
\hline $\begin{array}{l}\text { Mark A. van } \\
\text { Buchem, } \\
\text { MD, PhD }\end{array}$ & $\begin{array}{l}\text { Leiden } \\
\text { University, the } \\
\text { Netherlands }\end{array}$ & Author & $\begin{array}{l}\text { Data collection, } \\
\text { data } \\
\text { interpretation, } \\
\text { revising of the } \\
\text { manuscript }\end{array}$ \\
\hline $\begin{array}{l}\text { Charles } \\
\text { DeCarli, MD }\end{array}$ & $\begin{array}{l}\text { University of } \\
\text { California-Davis }\end{array}$ & Author & $\begin{array}{l}\text { Data } \\
\text { interpretation, } \\
\text { revising of the } \\
\text { manuscript }\end{array}$ \\
\hline $\begin{array}{l}\text { Ding Ding, } \\
\text { MPH, PhD }\end{array}$ & $\begin{array}{l}\text { Fudan University, } \\
\text { Shanghai, China }\end{array}$ & Author & $\begin{array}{l}\text { Data collection, } \\
\text { data } \\
\text { interpretation, } \\
\text { revising of the } \\
\text { manuscript }\end{array}$ \\
\hline $\begin{array}{l}\text { Villi } \\
\text { Gudnason, } \\
\text { MD, PhD }\end{array}$ & $\begin{array}{l}\text { Icelandic Heart } \\
\text { Association, } \\
\text { Kopavogur; and } \\
\text { University of } \\
\text { Iceland, } \\
\text { Reykjavik, } \\
\text { Iceland }\end{array}$ & Author & $\begin{array}{l}\text { Data collection, } \\
\text { data } \\
\text { interpretation, } \\
\text { revising of the } \\
\text { manuscript }\end{array}$ \\
\hline $\begin{array}{l}\text { Hideo Hara, } \\
\text { MD, PhD }\end{array}$ & $\begin{array}{l}\text { Saga University, } \\
\text { Japan }\end{array}$ & Author & $\begin{array}{l}\text { Data } \\
\text { interpretation, } \\
\text { revising of the } \\
\text { manuscript }\end{array}$ \\
\hline $\begin{array}{l}\text { Toshio } \\
\text { Imaizumi, } \\
\text { MD, PhD }\end{array}$ & $\begin{array}{l}\text { Kushiro City } \\
\text { General Hospital, } \\
\text { Japan }\end{array}$ & Author & $\begin{array}{l}\text { Data collection, } \\
\text { data } \\
\text { interpretation, } \\
\text { revising of the } \\
\text { manuscript }\end{array}$ \\
\hline $\begin{array}{l}\text { Katsuhiko } \\
\text { Kohara, MD, } \\
\text { PhD }\end{array}$ & $\begin{array}{l}\text { Ehime } \\
\text { University, } \\
\text { Matsuyama, } \\
\text { Japan }\end{array}$ & Author & $\begin{array}{l}\text { Data collection, } \\
\text { data } \\
\text { interpretation, } \\
\text { revising of the } \\
\text { manuscript }\end{array}$ \\
\hline $\begin{array}{l}\text { Hyung-Min } \\
\text { Kwon, MD, } \\
\text { PhD }\end{array}$ & $\begin{array}{l}\text { SMG-SNU } \\
\text { Boramae } \\
\text { Medical Center, } \\
\text { Seoul, Republic } \\
\text { of Korea }\end{array}$ & Author & $\begin{array}{l}\text { Data collection, } \\
\text { data } \\
\text { interpretation, } \\
\text { revising of the } \\
\text { manuscript }\end{array}$ \\
\hline $\begin{array}{l}\text { Lenore J. } \\
\text { Launer, PhD }\end{array}$ & $\begin{array}{l}\text { National Institute } \\
\text { on Aging, } \\
\text { Bethesda, MD }\end{array}$ & Author & $\begin{array}{l}\text { Data collection, } \\
\text { data } \\
\text { interpretation, } \\
\text { revising of the } \\
\text { manuscript }\end{array}$ \\
\hline $\begin{array}{l}\text { Vincent } \\
\text { Mok, MD, } \\
\text { PhD }\end{array}$ & $\begin{array}{l}\text { The Chinese } \\
\text { University of } \\
\text { Hong Kong, } \\
\text { China }\end{array}$ & Author & $\begin{array}{l}\text { Data collection, } \\
\text { data } \\
\text { interpretation, } \\
\text { revising of the } \\
\text { manuscript }\end{array}$ \\
\hline $\begin{array}{l}\text { Thanh Phan, } \\
\text { PhD }\end{array}$ & $\begin{array}{l}\text { Monash } \\
\text { University, } \\
\text { Melbourne, } \\
\text { Australia }\end{array}$ & Author & $\begin{array}{l}\text { Data } \\
\text { interpretation, } \\
\text { revising of the } \\
\text { manuscript }\end{array}$ \\
\hline $\begin{array}{l}\text { Sarah R } \\
\text { Preis, ScD }\end{array}$ & $\begin{array}{l}\text { Boston } \\
\text { University and } \\
\text { the NHLBI's } \\
\text { Framingham } \\
\text { Heart Study, MA }\end{array}$ & Author & $\begin{array}{l}\text { Data } \\
\text { interpretation, } \\
\text { revising of the } \\
\text { manuscript }\end{array}$ \\
\hline $\begin{array}{l}\text { José Rafael } \\
\text { Romero, MD }\end{array}$ & $\begin{array}{l}\text { Boston } \\
\text { University and } \\
\text { the NHLBI's } \\
\text { Framingham } \\
\text { Heart Study, MA }\end{array}$ & Author & $\begin{array}{l}\text { Data collection, } \\
\text { data } \\
\text { interpretation, } \\
\text { revising of the } \\
\text { manuscript }\end{array}$ \\
\hline
\end{tabular}

Appendix (continued)

\begin{tabular}{|c|c|c|c|}
\hline Name & Location & Role & Contribution \\
\hline $\begin{array}{l}\text { Sudha } \\
\text { Seshadri, } \\
\text { MD }\end{array}$ & $\begin{array}{l}\text { Boston } \\
\text { University and } \\
\text { the NHLBI's } \\
\text { Framingham } \\
\text { Heart Study, MA }\end{array}$ & Author & $\begin{array}{l}\text { Data collection, } \\
\text { data } \\
\text { interpretation, } \\
\text { revising of the } \\
\text { manuscript }\end{array}$ \\
\hline $\begin{array}{l}\text { Velandai } \\
\text { Srikanth, } \\
\text { MD, PhD }\end{array}$ & $\begin{array}{l}\text { Monash } \\
\text { University, } \\
\text { Melbourne, } \\
\text { Australia }\end{array}$ & Author & $\begin{array}{l}\text { Data collection, } \\
\text { data } \\
\text { interpretation, } \\
\text { revising of the } \\
\text { manuscript }\end{array}$ \\
\hline $\begin{array}{l}\text { Yuki } \\
\text { Takashima, } \\
\text { MD, PhD }\end{array}$ & $\begin{array}{l}\text { Hizen Psychiatric } \\
\text { Center, Saga, } \\
\text { Japan }\end{array}$ & Author & $\begin{array}{l}\text { Data collection, } \\
\text { data } \\
\text { interpretation, } \\
\text { revising of the } \\
\text { manuscript }\end{array}$ \\
\hline $\begin{array}{l}\text { Yoshito } \\
\text { Tsushima, } \\
\text { MD, PhD }\end{array}$ & $\begin{array}{l}\text { Gunma } \\
\text { University, } \\
\text { Maebashi, Japan }\end{array}$ & Author & $\begin{array}{l}\text { Data collection, } \\
\text { data } \\
\text { interpretation, } \\
\text { revising of the } \\
\text { manuscript }\end{array}$ \\
\hline $\begin{array}{l}\text { Zhaolu } \\
\text { Wang, PhD }\end{array}$ & $\begin{array}{l}\text { The Chinese } \\
\text { University of } \\
\text { Hong Kong, } \\
\text { China }\end{array}$ & Author & $\begin{array}{l}\text { Data collection, } \\
\text { data } \\
\text { interpretation, } \\
\text { revising of the } \\
\text { manuscript }\end{array}$ \\
\hline $\begin{array}{l}\text { Philip A. } \\
\text { Wolf, MD }\end{array}$ & $\begin{array}{l}\text { Boston } \\
\text { University and } \\
\text { the NHLBI's } \\
\text { Framingham } \\
\text { Heart Study, MA }\end{array}$ & Author & $\begin{array}{l}\text { Data } \\
\text { interpretation, } \\
\text { revising of the } \\
\text { manuscript }\end{array}$ \\
\hline $\begin{array}{l}\text { Yunyun } \\
\text { Xiong, MD, } \\
\text { PhD }\end{array}$ & $\begin{array}{l}\text { The Chinese } \\
\text { University of } \\
\text { Hong Kong, } \\
\text { China }\end{array}$ & Author & $\begin{array}{l}\text { Data } \\
\text { interpretation, } \\
\text { revising of the } \\
\text { manuscript }\end{array}$ \\
\hline $\begin{array}{l}\text { Shuhei } \\
\text { Yamaguchi, } \\
\text { MD, PhD }\end{array}$ & $\begin{array}{l}\text { Shimane } \\
\text { University, } \\
\text { Izumo, Japan }\end{array}$ & Author & $\begin{array}{l}\text { Data collection, } \\
\text { data } \\
\text { interpretation, } \\
\text { revising of the } \\
\text { manuscript }\end{array}$ \\
\hline $\begin{array}{l}\text { David J } \\
\text { Werring, } \\
\text { FRCP, PhD }\end{array}$ & UCL, London, UK & $\begin{array}{l}\text { Author, } \\
\text { director of the } \\
\text { study, } \\
\text { corresponding } \\
\text { author }\end{array}$ & $\begin{array}{l}\text { Study concept } \\
\text { and design, } \\
\text { literature search, } \\
\text { data collection, } \\
\text { statistical } \\
\text { analysis, } \\
\text { interpretation of } \\
\text { data, drafting/ } \\
\text { revising of the } \\
\text { manuscript, had } \\
\text { full access to all } \\
\text { the data in the } \\
\text { study and takes } \\
\text { responsibility for } \\
\text { the integrity of } \\
\text { the data and the } \\
\text { accuracy of the } \\
\text { data analysis }\end{array}$ \\
\hline
\end{tabular}

\section{References}

1. Pantoni L. Cerebral small vessel disease: from pathogenesis and clinical characteristics to therapeutic challenges. Lancet Neurol 2010;9:689-701.

2. Yakushiji Y, Werring DJ. Cerebrovascular disease: lobar cerebral microbleeds signal early cognitive impairment. Nat Rev Neurol 2016;12:680-682.

3. Fazekas F, Kleinert R, Roob G, et al. Histopathologic analysis of foci of signal loss on gradient-echo $\mathrm{T} 2{ }^{*}$-weighted $\mathrm{MR}$ images in patients with spontaneous intracerebral hemorrhage: evidence of microangiopathy-related microbleeds. AJNR Am J Neuroradiol 1999;20:637-642. 
4. Cordonnier C, Al-Shahi Salman R, Wardlaw J. Spontaneous brain microbleeds: systematic review, subgroup analyses and standards for study design and reporting. Brain 2007;130:1988-2003.

5. Greenberg SM, Vernooij MW, Cordonnier C, et al. Cerebral microbleeds: a guide to detection and interpretation. Lancet Neurol 2009;8:165-174.

6. Knudsen KA, Rosand J, Karluk D, Greenberg SM. Clinical diagnosis of cerebral amyloid angiopathy: validation of the Boston criteria. Neurology 2001;56:537-539.

7. Vernooij MW, van der Lugt A, Ikram MA, et al. Prevalence and risk factors of cerebral microbleeds: the Rotterdam Scan Study. Neurology 2008;70:1208-1214.

8. Yakushiji Y, Yokota C, Yamada N, Kuroda Y, Minematsu K. Clinical characteristics by topographical distribution of brain microbleeds, with a particular emphasis on diffuse microbleeds. J Stroke Cerebrovasc Dis 2011;20:214-221.

9. van Asch CJ, Luitse MJ, Rinkel GJ, van der Tweel I, Algra A, Klijn CJ. Incidence, case fatality, and functional outcome of intracerebral haemorrhage over time, according to age, sex, and ethnic origin: a systematic review and meta-analysis. Lancet Neurol 2010 9:167-176.

10. Feigin V, Carter K, Hackett M, et al. Ethnic disparities in incidence of stroke subtypes: Auckland regional community stroke study, 2002-2003. Lancet Neurol 2006;5: 130-139.

11. Yakushiji $\mathrm{Y}$, Noguchi $\mathrm{T}$, Hara M, et al. Distributional impact of brain microbleeds on global cognitive function in adults without neurological disorder. Stroke 2012;43: $1800-1805$.

12. Charidimou A, Shoamanesh A. Ethnicity and neuroimaging markers of cerebral small vessel disease: neglected but clinically important. Int J Stroke 2015;10:E34

13. Stewart LA, Clarke M, Rovers M, et al. Preferred Reporting Items for Systematic Review and Meta-Analyses of Individual Participant Data: the PRISMA-IPD statement. JAMA 2015;313:1657-1665

14. Stroup DF, Berlin JA, Morton SC, et al. Meta-analysis of observational studies in epidemiology: a proposal for reporting: Meta-analysis of Observational Studies in Epidemiology (MOOSE) group. JAMA 2000;283:2008-2012.

15. Microbleeds International Collaborative Network. Worldwide collaboration in the Microbleeds International Collaborative Network. Lancet Neurol 2016;15: 1113-1114

16. Tsushima Y, Tanizaki Y, Aoki J, Endo K. MR detection of microhemorrhages in neurologically healthy adults. Neuroradiology 2002;44:31-36.

17. Horita Y, Imaizumi T, Niwa J, et al. Analysis of dot-like hemosiderin spots using brain dock system [in Japanese]. No Shinkei Geka 2003;31:263-267.

18. Ochi N, Tabara Y, Igase M, et al. Silent cerebral microbleeds associated with arterial stiffness in an apparently healthy subject. Hypertens Res 2009;32:255-260.

19. Bokura H, Saika R, Yamaguchi T, et al. Microbleeds are associated with subsequen hemorrhagic and ischemic stroke in healthy elderly individuals. Stroke 2011;42: 1867-1871.

20. Takashima Y, Mori T, Hashimoto M, et al. Clinical correlating factors and cognitive function in community-dwelling healthy subjects with cerebral microbleeds. J Stroke Cerebrovasc Dis 2011;20:105-110.

21. Kim CK, Kwon HT, Kwon HM. No significant association of aspirin use with cerebral microbleeds in the asymptomatic elderly. J Neurol Sci 2012;319:56-58.

22. Mok V, Ding D, Fu J, et al. Transcranial Doppler ultrasound for screening cerebral small vessel disease: a community study. Stroke 2012;43:2791-2793.

23. Qiu C, Cotch MF, Sigurdsson S, et al. Retinal and cerebral microvascular signs and diabetes: the Age, Gene/Environment Susceptibility-Reykjavik study. Diabetes 2008 57:1645-1650.

24. Choi P, Ren M, Phan TG, et al. Silent infarcts and cerebral microbleeds modify the associations of white matter lesions with gait and postural stability: population-based study. Stroke 2012;43:1505-1510.

25. Romero JR, Preis SR, Beiser A, et al. Risk factors, stroke prevention treatments, and prevalence of cerebral microbleeds in the Framingham Heart Study. Stroke 2014;45: 1492-1494.
26. Roob G, Schmidt R, Kapeller P, Lechner A, Hartung HP, Fazekas F. MRI evidence of past cerebral microbleeds in a healthy elderly population. Neurology 1999;52: 991-994.

27. Akoudad S, de Groot M, Koudstaal PJ, et al. Cerebral microbleeds are related to loss of white matter structural integrity. Neurology 2013;81:1930-1937.

28. Gregoire SM, Chaudhary UJ, Brown MM, et al. The Microbleed Anatomical Rating Scale (MARS): reliability of a tool to map brain microbleeds. Neurology 2009;73: 1759-1766.

29. Cordonnier C, Potter GM, Jackson CA, et al. Improving interrater agreement about brain microbleeds: development of the Brain Observer MicroBleed Scale (BOMBS). Stroke 2009;40:94-99.

30. Kim M, Bae HJ, Lee J, et al. APOE epsilon2/epsilon4 polymorphism and cerebral microbleeds on gradient-echo MRI. Neurology 2005;65:1474-1475.

31. Ding D, Zhao Q, Guo Q et al. The Shanghai Aging Study: study design, baseline characteristics, and prevalence of dementia. Neuroepidemiology 2014;43:114-122.

32. Hafsteinsdottir SH, Eiriksdottir G, Sigurdsson S, et al. Brain tissue volumes by APOE genotype and leisure activity: the AGES-Reykjavik Study. Neurobiol Aging 2012;33: 829 e821-828.

33. Guo H, Tabara Y, Igase M, et al. Abnormal nocturnal blood pressure profile is associated with mild cognitive impairment in the elderly: the J-SHIPP study. Hypertens Res 2010;33:32-36.

34. Poels MM, Ikram MA, van der Lugt A, et al. Cerebral microbleeds are associated with worse cognitive function: the Rotterdam Scan Study. Neurology 2012;78:326-333.

35. Chobanian AV, Bakris GL, Black HR, et al. The seventh report of the Joint National Committee on Prevention, Detection, Evaluation, and Treatment of High Blood Pressure: the JNC 7 report. JAMA 2003;289:2560-2572.

36. Wells GA, Shea B, O'Connell D, et al. The Newcastle-Ottawa Scale (NOS) for assessing the quality if nonrandomized studies in meta-analyses. 2009. Available at: www.ohri.ca/programs/clinical_epidemiology/oxford.htm.

37. Copenhaver BR, Hsia AW, Merino JG, et al. Racial differences in microbleed prevalence in primary intracerebral hemorrhage. Neurology 2008;71:1176-1182.

38. Mok V, Srikanth V, Xiong Y, et al. Race-ethnicity and cerebral small vessel disease: comparison between Chinese and white populations. Int J Stroke 2014;100:36-42.

39. Wiegman AF, Meier IB, Schupf N, et al. Cerebral microbleeds in a multiethnic elderly community: demographic and clinical correlates. J Neurol Sci 2014;345:125-130.

40. Jones DW. Hypertension in East Asia. Am J Hypertens 1995;8:111s-114s.

41. Coutinho T, Turner ST, Mosley TH, Kullo IJ. Biomarkers associated with pulse pressure in African Americans and non-Hispanic whites. Am J Hypertens 2012;25:145-151.

42. Eirin A, Zhu XY, Woollard JR, et al. Increased circulating inflammatory endothelial cells in blacks with essential hypertension. Hypertension 2013;62:585-591.

43. Lee DS, Larson MG, Lunetta KL, et al. Clinical and genetic correlates of soluble P-selectin in the community. J Thromb Haemost 2008;6:20-31.

44. Rouhl RP, Damoiseaux JG, Lodder J, et al. Vascular inflammation in cerebral small vessel disease. Neurobiol Aging 2012;33:1800-1806.

45. Chen YW, Lee MJ, Smith EE. Cerebral amyloid angiopathy in East and West. Int J Stroke 2010;5:403-411.

46. Martinez-Ramirez S, Romero JR, Shoamanesh A, et al. Diagnostic value of lobar microbleeds in individuals without intracerebral hemorrhage. Alzheimers Dement $2015 ; 11: 1480-1488$

47. Gregoire SM, Werring DJ, Chaudhary UJ, et al. Choice of echo time on GRE T2* weighted MRI influences the classification of brain microbleeds. Clin Radiol 2010;65: 391-394

48. Winkleby MA, Kraemer HC, Ahn DK, Varady AN. Ethnic and socioeconomic differences in cardiovascular disease risk factors: findings for women from the Third National Health and Nutrition Examination Survey, 1988-1994. JAMA 1998;280 356-362.

49. Soo YO, Yang SR, Lam WW, et al. Risk vs benefit of anti-thrombotic therapy in ischaemic stroke patients with cerebral microbleeds. J Neurol 2008;255:1679-1686. 